Cite this: Inorg. Chem. Front., 2014, 1,178

Received 18th October 2013, Accepted 18th December 2013 DOI: $10.1039 / c 3 q i 00075 c$ rsc.li/frontiers-inorganic

\section{Self-assembly and structural transformations of high-nuclearity palladium-rich polyoxometalates $\uparrow$}

\author{
Jamie M. Cameron, $\$$ Jing Gao, \$ De-Liang Long* and Leroy Cronin*
}

A one-pot strategy exploiting the structure directing effects of $\mathrm{Se}^{\mathrm{IV}}$ and $\mathrm{Te}^{\mathrm{IV}}$ heteroatoms has yielded the highest nuclearity noble metal containing polyoxometalates to date; including the palladium-rich selenotungstate isomers $\mathrm{K}_{28}\left[\mathrm{H}_{12} \mathrm{Pd}_{10} \mathrm{Se}_{10} \mathrm{~W}_{52} \mathrm{O}_{206}\right] \cdot 65 \mathrm{H}_{2} \mathrm{O}(\mathbf{1})$ and $\mathrm{K}_{26}\left[\mathrm{H}_{14} \mathrm{Pd}_{10} \mathrm{Se}_{10} \mathrm{~W}_{52} \mathrm{O}_{206}\right] \cdot 68 \mathrm{H}_{2} \mathrm{O}(\mathbf{2})$, and the nanoscale tellurotungstate cluster $\mathrm{Na}_{40}\left[\mathrm{Pd}_{6} \mathrm{Te}_{19} \mathrm{~W}_{42} \mathrm{O}_{190}\right] \cdot 76 \mathrm{H}_{2} \mathrm{O}$ (3). These reaction systems exhibit remarkable structural flexibility and point to a new route towards the synthesis of complex heterometallic species, in which multiple lacunary polyoxometalate 'building blocks' have been assembled to trap a transient oxopalladate species suspected to play a role in the assembly of several common polyoxopalladates. Mass spectrometry has been applied to explore and compare the solution stability of compounds $\mathbf{1 - 3}$, demonstrating the markedly different properties of the $\mathrm{Se}^{\mathrm{IV}}$ and $\mathrm{Te}^{\mathrm{IV}}$ templated systems. Electrochemical analysis of 1 has been provided and is dominated by $\mathrm{Pd}$ redox processes, with reduction of the cluster resulting in electrodeposition of $\mathrm{Pd}$ metal and observation of the subsequent formation of $\mathrm{PdO}$ species, concurrent with previously reported oxopalladate containing species.

\section{Introduction}

Polyoxometalates (POMs) are an important class of polynuclear anionic metal-oxo clusters commonly formed via the assembly of small oxometalate units (traditionally W, Mo or V) into large and often remarkably complex architectures, frequently by careful control of the reaction parameters under one-pot conditions. ${ }^{1}$ The explosion in the number of publications concerning POMs over the last decade has, however, largely arisen as a result of the suitability of pre-formed lacunary POM clusters in which vacancies in the cluster shell can be occupied by additional metal ions or may support the formation of larger metal moieties - to act as discrete 'secondary building units' in the formation of increasingly diverse higher-nuclearity mixed-metal clusters, commonly referred to as 'transition metal substituted POMs' (TMSPs). ${ }^{2}$ The degree of control over both structure and functionality that this promises has seen TMSPs explored at considerable length for use across a wide

WestCHEM, School of Chemistry, The University of Glasgow, Glasgow, G12 8QQ, UK. E-mail: Deliang.Long@glasgow.ac.uk,Lee.Cronin@glasgow.ac.uk; http://www.croninlab.com; Fax: (+44) (0)141-330-4888; Tel: (+44) (0)141-330-6650

$\dagger$ Electronic supplementary information (ESI) available: Crystallographic data and refinement parameters, ESI-MS experimental details and full assignments, discussion of structure, assembly and solution transformations of 3, cyclic voltammetry. ICSD 426772-426774. For ESI and crystallographic data in CIF or other electronic format see DOI: $10.1039 / \mathrm{c} 3 q i 00075 \mathrm{c}$

$\$$ These authors contributed equally towards the preparation of this manuscript. spectrum of fields ranging from catalysis to medical and material sciences to name but three. ${ }^{3}$

Central to the assembly and function of these diverse heteropolyoxometalate (HPOM) 'building blocks' are the heteroatom species which template their formation. ${ }^{4}$ Recent years have seen a vast array of different elements from almost every group of the periodic table employed in this way, ${ }^{5}$ in which the electronic configuration of the heteroatom can have a profound effect on the self-assembly of the POM cluster, sometimes imparting specific function or properties to the oxometalate framework in the process. ${ }^{6}$ Notably, lone-pair containing heteroatoms (such as $\mathrm{As}^{\mathrm{III}}, \mathrm{Se}^{\mathrm{IV}}$ or $\mathrm{Te}^{\mathrm{IV}}$ etc.) have been intensively exploited recently as a means by which lacunary clusters can be generated without the need for hydrolysis of a pre-existing parent clusters, allowing for the preparation of unique, often high nuclearity POM architectures ${ }^{7}$ and for further expansion of the class of TMSP materials. ${ }^{8}$

In particular, the incorporation of catalytically active noble metals (primarily $\mathrm{Ru}$ and Pd) within discrete POM units has attracted increasing attention as a means by which new functional and solution-stable catalytic materials might be discovered. ${ }^{9,10}$ Hill, Kortz and others have pioneered the study of well-defined lacunary POMs which form a range of novel noble metal containing species, ${ }^{11}$ two comprehensive reviews of which have been published recently and summarise these efforts. ${ }^{12}$ It is also important to note that some $\mathrm{Pd}^{\mathrm{II}}$ species may comprise a fascinating subset of POM chemistry and primarily along with Kortz and coworkers, ${ }^{13}$ our own group has 
demonstrated how palladium can form a range of remarkable oxopalladate clusters including the giant, nanoscale $\left\{\mathrm{Pd}_{84}\right\}$ wheel. ${ }^{14}$ These clusters are especially interesting in that they follow a quite different set of structural principles to more conventional POMs and in fact, the guiding building block concepts for this class of compounds are far less well-defined than those of polyoxotungstates. To date, however, the synthesis and characterisation of both noble metal containing POMs and polyoxopalladates remains relatively underexplored, particularly in comparison to the rich array of reported $1^{\text {st }}$ row transition metal containing species.

Herein, we present three new, nanoscale, palladium-rich POM clusters synthesised via a facile one-pot approach which exploits the structure-directing effects of the group XVI heteroatoms, $\mathrm{Se}^{\mathrm{IV}}$ and $\mathrm{Te}^{\mathrm{IV}}$.

\section{Results and discussion}

\section{Selenite templated species}

Crystallographic analysis of $\mathbf{1}$ reveals that it crystallises in a triclinic system with the space group $P \overline{1}$ and exhibits two distinct pairs of lacunary tungstate units linked by three cornersharing $\left\{\mathrm{WO}_{6}\right\}$ octahedra to form two equivalent $\left\{\mathrm{Se}_{3} \mathrm{~W}_{26}\right\}$ units. These superlacunary selenotungstate species are bridged by two identical $\left\{\mathrm{Pd}_{5} \mathrm{Se}_{2}\right\}$ moieties to form an overall architecture with nominal $C_{2 \mathrm{~h}}$ symmetry (Fig. 1). The identical $\left\{\mathrm{Se}_{3} \mathrm{~W}_{26}\right\}$ units are related to each other in the structure of $\mathbf{1}$ by a $180^{\circ}$ rotation around the vertical axis of the molecule (as depicted in Fig. 1) and as a result, 1 can effectively be described as being in a trans-conformation about the central cavity with two pairs of cluster 'building blocks' located on trans positions (note the colour differences). The two

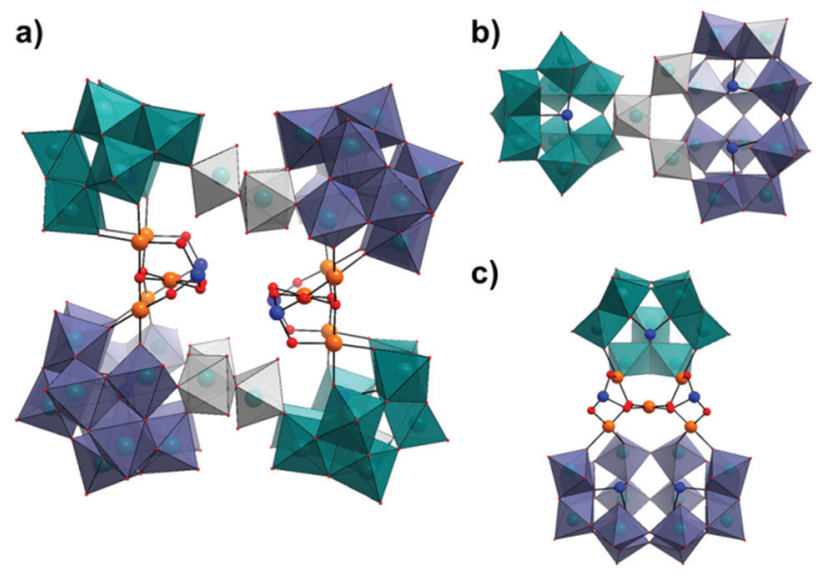

Fig. 1 Combined polyhedral/ball and stick representation of the structure of 1 showing; (a) front view of the intact cluster $\left[\mathrm{H}_{12} \mathrm{Pd}_{10} \mathrm{Se}_{10} \mathrm{~W}_{52} \mathrm{O}_{206}\right]^{28-}$, (b) top-down view of one $\left\{\mathrm{Se}_{3} \mathrm{~W}_{26}\right\}$ half-unit and, (c) side-on view of the $\left(\left\{\mathrm{SeW}_{9}\right\}\left\{\mathrm{Pd}_{5} \mathrm{Se}_{2}\right\}\left\{\mathrm{Se}_{2} \mathrm{~W}_{14}\right\}\right)$ half-unit with the $\left(\mathrm{WO}_{6}\right)$ linkers removed for clarity. (Colour code: $\left\{\mathrm{SeW}_{9}\right\}$ units: teal polyhedra, $\left\{\mathrm{Se}_{2} \mathrm{~W}_{14}\right\}$ units: purple polyhedra, $\mathrm{WO}_{6}$ linkers: grey polyhedra, $\mathrm{Pd}=$ orange, $\mathrm{Se}=$ blue, $\mathrm{O}=$ red. Cations and water molecules have been omitted for clarity.) component selenotungstate 'building blocks' can be classified as either the tri-lacunary $\mathrm{B}-\alpha-\left\{\mathrm{SeW}_{9} \mathrm{O}_{33}\right\}$ derivative of the $\mathrm{W}_{12}$ Keggin parent structure or the tetra-lacunary $\left\{\mathrm{Se}_{2} \mathrm{~W}_{14} \mathrm{O}_{52}\right\}$ derivative of the $\mathrm{W}_{18}$-'Trojan Horse' structure $^{6 b, 15}$ which, to the best of our knowledge, is the first time that this species has been observed in the solid state. Of particular interest are the unusual $\left\{\mathrm{Pd}_{5} \mathrm{Se}_{2}\right\}$ cores which are each supported by one $\left\{\mathrm{SeW}_{9}\right\}$ and one $\left\{\mathrm{Se}_{2} \mathrm{~W}_{14}\right\}$ fragment from opposing $\left\{\mathrm{Se}_{3} \mathrm{~W}_{26}\right\}$ units and are themselves directly related via a $180^{\circ}$ rotation along the horizontal axis of the molecule. All five $\mathrm{Pd}^{\mathrm{II}}$ ions within each $\left\{\mathrm{Pd}_{5} \mathrm{Se}_{2}\right\}$ unit exist in a square planar geometry coordinated by four oxygen atoms with an average $\mathrm{Pd}-\mathrm{O}$ bond length of 1.999(3) A. The coordination of those four palladium atoms which are bound directly to the lacunary POM fragments conforms largely to that observed previously in the literature for comparable systems, ${ }^{11 c, e}$ in which the $\mathrm{Pd}^{\mathrm{II}}$ ion either forms a bond to oxo-groups on neighbouring $\left\{\mathrm{W}_{3}\right\}$ triads in the case of $\left\{\mathrm{SeW}_{9}\right\}$, or similarly, to both the cap and belt regions of the $\left\{\mathrm{Se}_{2} \mathrm{~W}_{14}\right\}$ unit (Fig. 1c). The fifth $\mathrm{Pd}^{\mathrm{II}}$ ion in each unit sits roughly perpendicular to the aforementioned palladium atoms, linking them via two shared $\mu_{3}$-oxo bridges, whilst two pyramidal $\mathrm{Se}^{\mathrm{IV}}$ ions cap the remaining available oxo groups, effectively stabilising the overall $\left\{\mathrm{Pd}_{5} \mathrm{Se}_{2}\right\}$ unit.

Furthermore, whilst we believe that this is the first reported example of this type of $\left\{\mathrm{Pd}_{5} \mathrm{Se}_{2}\right\}$ moiety, it is particularly interesting to note that it is also possible to consider this structural unit as a key building block in the related field of polyoxopalladate chemistry. The previously reported family of palladate cages with the general formula $\left[\mathrm{MPd}_{12} \mathrm{O}_{8}\left(\mathrm{XO}_{y}\right)_{8}\right]^{n-1},{ }^{13 a, c-f}$ and the related series of Pd-'nanostars, ${ }^{13 b, 14 a, 16}$ of general formula $\left[\mathrm{Pd}_{17-x} \mathrm{O}_{10}\left(\mathrm{XO}_{y}\right)_{10}\right]^{n-}(\mathrm{X}=\mathrm{P}$, As or $\mathrm{Se})$, may both be viewed as assembling via the fusion of either four or five $\left\{\mathrm{Pd}_{5} \mathrm{X}_{2}\right\}$ units respectively, in which the capping heteroatoms form the vertices of the double diamond/star-like topology found in these species (Fig. 2). Comparatively, the $\left\{\mathrm{Pd}_{5} \mathrm{Se}_{2}\right\}$ unit in 1 shows noticeable distortion as a result of the unequal binding sites provided by the $\left\{\mathrm{SeW}_{9}\right\}$ and $\left\{\mathrm{Se}_{2} \mathrm{~W}_{14}\right\}$ units and exhibits a marked structural asymmetry in comparison to the analogous repeating structural units found in $\left\{\mathrm{Pd}_{12-17}\right\}$ which possess a notional $C_{2 \mathrm{v}}$ symmetry. This observation seems especially relevant from a mechanistic point of view, providing both a second perspective on the possible mechanisms of polyoxopalladate cluster growth and posing an intriguing 'chicken-and-egg' question in terms of which structural units (i.e. palladate or tungstate) play the most important role in the assembly of $\mathbf{1}$.

It should also be noted that the structure directing effect of the $\left[\mathrm{SeO}_{3}\right]^{2-}$ template is crucially important in this system, whereby through careful control of the reaction conditions we have been able to generate and combine multiple lacunary building blocks with additional heterometal atoms in situ. The lone pair on the template $\mathrm{Se}^{\mathrm{IV}}$ ions often precludes the formation of 'closed' POM species such as the Keggin or WellsDawson clusters, instead favouring the formation of multiple lacunary species over a wide range of conditions. These species can then be isolated (or 'trapped') either by addition of 
a)

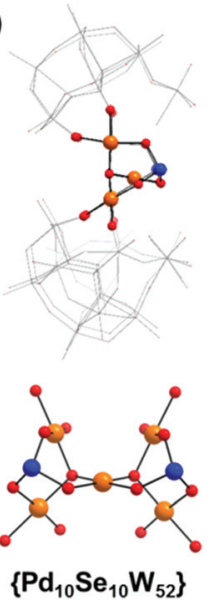

b)
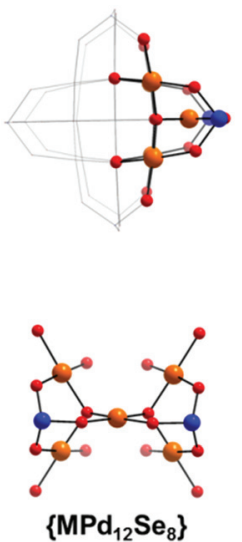

c)
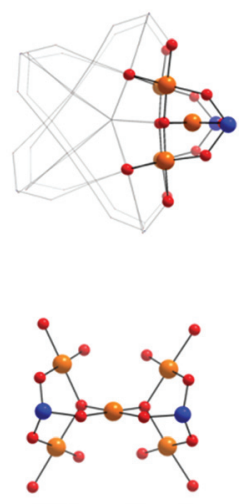

$\left\{\mathrm{Pd}_{15-17} \mathrm{Se}_{10}\right\}$

Fig. 2 Comparison of the selenopalladate structural units common to both compounds 1 and 2 and the polyoxopalladate 'cages' and 'nanostars' of the general formulae shown. ${ }^{13 f, g, 16}$ The supporting POM framework/surrounding oxopalladate cluster associated with each $\left\{\mathrm{Pd}_{5} \mathrm{Se}_{2}\right\}$ unit is shown in wireframe, providing an idea of the local environment of each unit. In the case of the polyoxopalladate clusters, it can clearly be seen how the $\left\{\mathrm{Pd}_{5} \mathrm{Se}_{2}\right\}$ moiety can be considered as a repeating structural unit in which either; (b) four or (c) five selenopalladate groups are fused to form the overall structure in which the central Pd" ion defines the four-or five-fold symmetry axes of the respective polyoxopalladate clusters. (Colour code: $\mathrm{Pd}=$ orange, $\mathrm{Se}=$ blue and $\mathrm{O}=$ red.)

heterometals capable of occupying the vacancies in the POM framework or by allowing the tungstate lacuna to condense together into a larger cluster unit, occasionally involving the abstraction of additional tungstate ions present in solution. ${ }^{7,8}$ Whilst the concept of using lone pair containing heteroatoms in this way is not entirely new, we believe that this work is the first time that multiple lacunary building blocks derived from different parent species (i.e. Keggin- or Wells-Dawson-type clusters) have been combined into a single POM architecture. ${ }^{17}$ This is significant, both in that it may provide a pathway for the isolation of unusual heterometal species (such as the $\left\{\mathrm{Pd}_{5} \mathrm{Se}_{2}\right\}$ core in 1) but also in that it indicates the hitherto unreported combinatorial nature of such systems, in which a series of inequivalent, metastable POM fragments are present and may be simultaneously accessed under the correct set of conditions.

On continued evaporation of the mother liquor from which the crystals of $\mathbf{1}$ were isolated, a second batch of product, $\mathrm{K}_{26}\left[\mathrm{H}_{14} \mathrm{Pd}_{10} \mathrm{Se}_{10} \mathrm{~W}_{52} \mathrm{O}_{206}\right] \cdot 68 \mathrm{H}_{2} \mathrm{O}$ (2), could be collected. Crystallographic analysis of compound 2 reveals that it is the structural cis-isomer of $\mathbf{1}$ and crystallises in a similar triclinic system with the space group $P \overline{1}$. In this species, the primary selenotungstate and $\left\{\mathrm{Pd}_{5} \mathrm{Se}_{2}\right\}$ building blocks have been conserved but undergone a reorganisation, notionally through a $180^{\circ}$ rotation of one complete $\left\{\left\{\mathrm{SeW}_{9}\right\}\left\{\mathrm{Pd}_{5} \mathrm{Se}_{2}\right\}\left\{\mathrm{Se}_{2} \mathrm{~W}_{14}\right\}\right\}$ unit about the clusters horizontal axis via cleaving of the $\left\{\mathrm{W}_{3}\right\}$ tungstate linkers reducing the overall symmetry of the cluster to $C_{2}$ (opposed to $C_{2 \mathrm{~h}}$ ) (Fig. 3). The $\left\{\mathrm{WO}_{6}\right\}$ octahedra which form the $\left\{\mathrm{W}_{3}\right\}$ linkers in $\mathbf{1}$ reorganise in compound 2 to form one corner-sharing $\left\{\mathrm{W}_{2}\right\}$ bridge between the two $\left\{\mathrm{SeW}_{9}\right\}$ fragments

a)

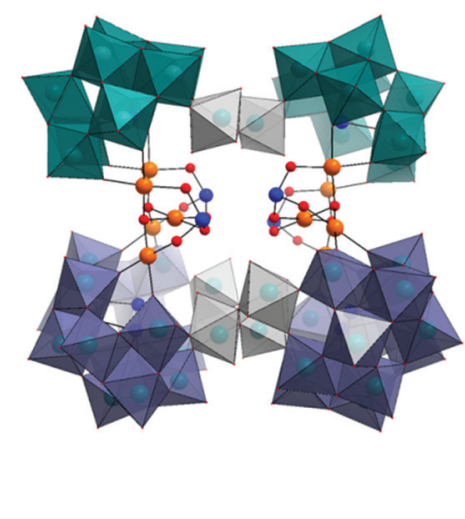

b)

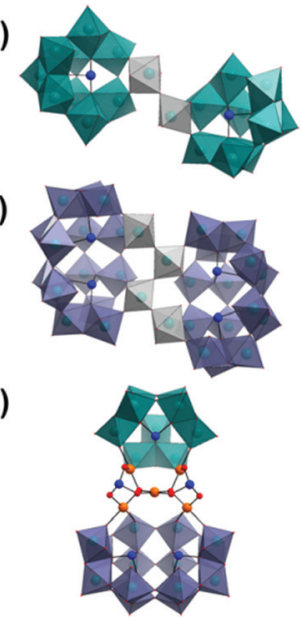

Fig. 3 Combined polyhedral/ball and stick representation of the structure of 2 showing; (a) front view of the intact cluster $\left[\mathrm{H}_{14} \mathrm{Pd}_{10} \mathrm{Se}_{10} \mathrm{~W}_{52} \mathrm{O}_{206}\right]^{28-}$, (b) top-down view of the $\left\{\mathrm{Se}_{2} \mathrm{~W}_{20}\right\}$ unit, (c) top-down view of the $\left\{\mathrm{Se}_{4} \mathrm{~W}_{32}\right\}$ unit and, (d) side-on view of the identical $\left(\left\{\mathrm{SeW}_{9}\right\}\left\{\mathrm{Pd}_{5} \mathrm{Se}_{2}\right\}\left\{\mathrm{Se}_{2} \mathrm{~W}_{14}\right\}\right)$ half-unit with the $\left(\mathrm{WO}_{6}\right)$ linkers removed for clarity. (Colour code: $\left\{\mathrm{SeW}_{9}\right\}$ units: teal polyhedra, $\left\{\mathrm{Se}_{2} \mathrm{~W}_{14}\right\}$ units: purple polyhedra, $\mathrm{WO}_{6}$ linkers: grey polyhedra, $\mathrm{Pd}=$ orange, $\mathrm{Se}=$ blue, $\mathrm{O}=$ red. Cations and water molecules have been omitted for clarity.)

to form a $\left\{\mathrm{Se}_{2} \mathrm{~W}_{20}\right\}$ unit, and one corner-sharing $\left\{\mathrm{W}_{4}\right\}$ unit which links the $\left\{\mathrm{Se}_{2} \mathrm{~W}_{14}\right\}$ units to yield a $\left\{\mathrm{Se}_{4} \mathrm{~W}_{32}\right\}$ species. In this way, it is conceivable to envisage the reorganisation of the entire cluster via breaking and reforming of just four $\mathrm{W}$-oxo bonds, namely those shared between the W-centres in the $\left\{\mathrm{W}_{3}\right\}$ linkers in $\mathbf{1}$ (shown in grey in Fig. 1 and 3). It seems possible therefore that the cis-isomer, 2, may be the thermodynamic product in this reaction system whilst the transisomer, $\mathbf{1}$, can be isolated first as the marginally less stable kinetic product. Whilst it may not be immediately apparent why this should be the case, it is possible to speculate that one explanation for the increased stability of $\mathbf{2}$ may be found in the respective configurations of both clusters and, specifically, the relationship of the two $\left\{\mathrm{Pd}_{5} \mathrm{Se}_{2}\right\}$ cores to each other. The apparent $180^{\circ}$ rotation of the $\left\{\left\{\mathrm{SeW}_{9}\right\}\left\{\mathrm{Pd}_{5} \mathrm{Se}_{2}\right\}\left\{\mathrm{Se}_{2} \mathrm{~W}_{14}\right\}\right\}$ half-unit in the formation of 2 leads the cis-isomer to adopt a 'staggered' configuration across the two halves of the molecule, whilst the two trans-related 'half-units' in $\mathbf{1}$ are eclipsed relative to another. Whilst at first glance, this seems to actually increase the steric constraints of the system (as evidenced by a slight reduction in the distances between the adjacent $\mathrm{Se}^{\mathrm{IV}}$ ions), this conformational change actually may subtly reduce the steric constraints within the central cavity of the cluster by reducing the number of chelating $\mathrm{K}^{+}$ions needed to stabilise the capping $\left[\mathrm{SeO}_{3}\right]^{2-}$ units from two to one (Fig. $\mathrm{S} 1 \dagger$ ), thus providing a possible thermodynamic driving force for the isomerisation to occur.

High resolution negative-mode electrospray ionisation mass spectrometry (ESI-MS) was used to confirm the structure and solution stability of compounds 1 and 2 in a $5: 95$ solution of water and acetonitrile. Unsurprisingly, the spectra of both clusters are very similar in which the majority of peaks are close 


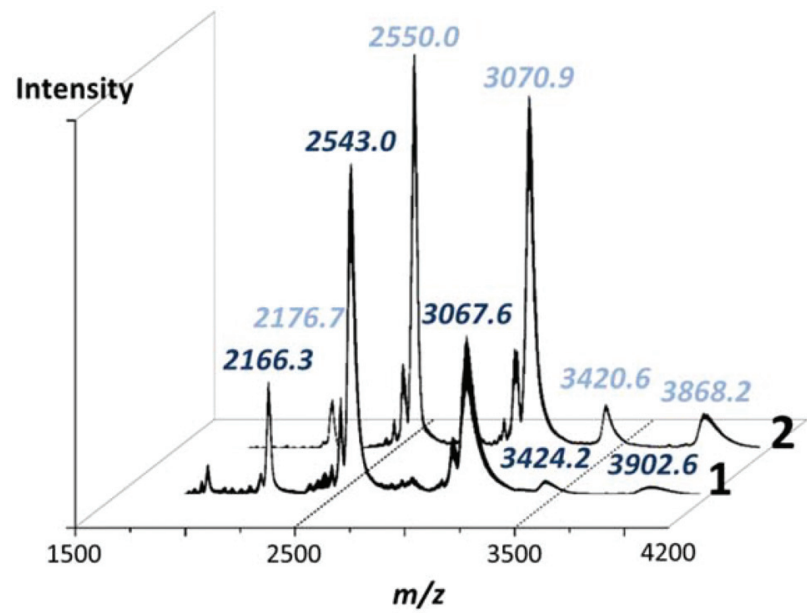

Fig. 4 Negative mode mass spectra of 1 and 2 in the $m / z$ range 1500 to 4200 showing the major peaks corresponding to the intact POM anions. Full assignment of the highlighted peaks is given in the ESI. $\dagger$

enough to effectively be considered as overlapping within the constraints of the experiment, whereby any small discrepancy is easily explained by the exchange of cations or, more frequently, associated solvate (Fig. 4). From these experiments it could be observed that both species retain their integrity in solution, with all of the major peaks identifiable in each spectrum corresponding to the intact POM cluster. Notably, the well-resolved major peaks in both spectra at $\mathrm{ca} .2550 \mathrm{~m} / \mathrm{z}$ correspond to the species $\left[\mathrm{H}_{17-x} \mathrm{~K}_{5+x}\left(\mathrm{H}_{12} \mathrm{Pd}_{10} \mathrm{Se}_{10} \mathrm{~W}_{52} \mathrm{O}_{206}\right) \cdot 18 \mathrm{H}_{2} \mathrm{O}\right]^{6-}$ and at higher $\mathrm{m} / \mathrm{z}$ ranges, species corresponding to a dimeric unit of both 1 and 2 can be identified at $c a .3400$ and $3900 \mathrm{~m} / \mathrm{z}$ (see ESI $\uparrow$ for detailed peak assignments). It should be noted that the high nuclearity and charge of these clusters makes direct assignment of the peak envelopes difficult, with most peak envelopes undergoing some degree of 'broadening' over a wider than expected $\mathrm{m} / \mathrm{z}$ range, generally as a result of the loss of weakly associated solvent molecules or cation exchange within the spectrometer causing multiple closely related peaks to overlap into a single, enlarged envelope. ${ }^{18}$

\section{Tellurite templated species}

Subsequent to the isolation of compounds $\mathbf{1}$ and $\mathbf{2}$ we were interested to see what effect substituting the $\mathrm{Se}^{\mathrm{IV}}$ heteroatoms for $\mathrm{Te}^{\mathrm{IV}}$ might have on this system. Following a similar one-pot approach we were able to isolate crystals of a quite different polyanion, $\mathrm{Na}_{40}\left[\mathrm{Pd}_{6} \mathrm{Te}_{19} \mathrm{~W}_{42} \mathrm{O}_{190}\right] \cdot 76 \mathrm{H}_{2} \mathrm{O}$ (3). Crystallographic analysis of compound 3 reveals that this cluster crystallises in a triclinic system with the space group $P \overline{1}$ in which the arrangement of the POM cluster exhibits an approximate $C_{3 \mathrm{~h}}$ symmetry (Fig. 5). In comparison to 1 and 2, 3 comprises only one type of lacunary tungstate unit, the rarely observed $\alpha-\left\{\mathrm{TeW}_{7} \mathrm{O}_{27}\right\}$, six of which are linked together by pendant $\left[\mathrm{TeO}_{3}\right]^{2-}$ groups to support two identical $\left\{\mathrm{Pd}_{3} \mathrm{Te}_{3} \mathrm{O}_{3}\right\}$ cores. Interestingly, the $\mathrm{Te}^{\mathrm{IV}}$ ions in compound 3 show three distinct coordination modes. The heteroatom templates within the a)

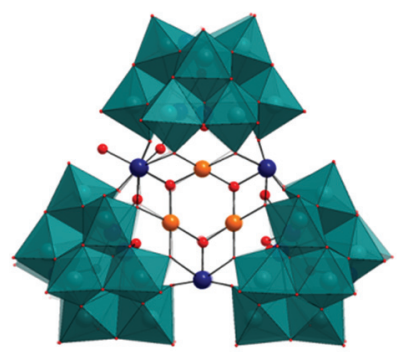

b)

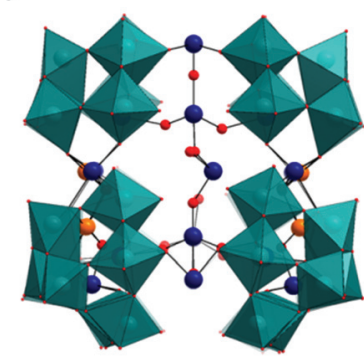

Fig. 5 Combined polyhedral/ball and stick representation of the structure of 3 showing; (a) front on view of the intact cluster $\left[\mathrm{Pd}_{6} \mathrm{Te}_{19} \mathrm{~W}_{42} \mathrm{O}_{190}\right]^{40-}$ highlighting the $\left\{\mathrm{Pd}_{3} \mathrm{Te}_{3} \mathrm{O}_{3}\right\}$ core and, (b) side-on view of the intact cluster showing the varied linking modes of the pendant $\mathrm{Te}^{\mathrm{IV}}$ groups. (Colour code: $\mathrm{WO}_{6}=$ teal polyhedra, $\mathrm{Pd}=$ orange, $\mathrm{Te}=$ dark blue, $\mathrm{O}=$ red. Cations and water molecules have been omitted for clarity.)

$\left\{\mathrm{TeW}_{7}\right\}$ units, which are analogous to species our group has reported previously, ${ }^{7 d}$ are remarkable in that they display an unusual highly distorted tetrahedral geometry rather than the more traditional pyramidal conformation as a result of an additional oxo bond shared with the pyramidal $\left\{\mathrm{TeO}_{3}\right\}$ linkers which bridge the tungstate units. This is the first known example of a non-pyramidal, four-coordinate $\mathrm{Te}^{\mathrm{IV}}$ ion templating a POM unit. The three $\mathrm{Te}^{\mathrm{IV}}$ ions in each $\left\{\mathrm{Pd}_{3} \mathrm{Te}_{3}\right\}$ core exist in a square pyramidal geometry in which the base of the pyramid forms a face linking two neighbouring $\left\{\mathrm{TeW}_{7}\right\}$ units via two shared oxo-bonds whilst the apex of the pyramid is occupied by a $\mu_{3}$-oxygen shared with two $\mathrm{Pd}^{\mathrm{II}}$ ions (Fig. S2 $\dagger$ ). Interestingly, the topology of the $\left\{\mathrm{Pd}_{3} \mathrm{Te}_{3}\right\}$ core in 3 bears little similarity to that in $\mathbf{1}$ and $\mathbf{2}$ and appears to be unrelated to any fragments previously observed in polyoxopalladate chemistry, suggesting that the assembly of $\mathbf{3}$ may be more strongly influenced by the formation of the tungstate lacuna and related substituted species than by possible concurrent, or competing, assembly processes of oxopalladate species in solution.

In the case of 3, negative mode ESI-MS yields a very different result than those recorded for clusters $\mathbf{1}$ and 2, hinting at the inherent instability of this species in solution. The mass spectrum of $\mathbf{3}$ appears to show heavy fragmentation of the parent species and in fact, no single peak can be identified that corresponds to the intact cluster, with the largest identifiable fragments occurring in a range between ca. 3-4 kDa (MW of $3=16.1 \mathrm{kDa}$ ) (Fig. S3, see Table S4 for selected peak assignments $\dagger$ ). One probable explanation for this behaviour are the obvious structural differences between the two types of clusters, specifically in that the primary structural units in $\mathbf{1}$ and $\mathbf{2}$ are linked by $\mathrm{W}-\mathrm{O}-\mathrm{W}$ and $\mathrm{Pd}-\mathrm{O}-\mathrm{Pd}$ bonds whereas the primary linkers in 3 are based on the significantly more labile Te-O-Te and Te-O-W bonds. This observation is also commensurate with our previously reported work on macrocyclic tellurotungstate clusters containing a similar $\left[\mathrm{TeW}_{7} \mathrm{O}_{28}\right]^{10-}$ moiety, in which the macrocyclic units readily fragment into smaller species and could not be identified intact, further hinting at the inherent lability of such 
$\left(\mathrm{TeO}_{x}\right)$ linked polyoxotungstate systems. ${ }^{7 d}$ Furthermore, the remarkable similarity in the fragmentation patterns of both 3 and the previously reported $\left[\mathrm{Te}_{8} \mathrm{~W}_{28} \mathrm{O}_{112}\right]^{24-}$ species allow us to postulate that these two clusters may share a similar assembly pathway (Fig. S4†). Our experiences of synthesising 3 also generally support the conclusion that this cluster is inherently unstable, chiefly in that despite our best efforts, optimising the synthesis of this cluster proved challenging as there seems to exist only a narrow window of conditions in which 3 can be reliably isolated and, though our final reported conditions are entirely reproducible, the total yield of crystalline product from each batch remains low. Furthermore, our attempts to modify the synthesis and associated efforts to recrystallize 3 often led to different products; notably including a structurally related, lower nuclearity cluster, $\left[\mathrm{Pd}_{6} \mathrm{Te}_{3} \mathrm{~W}_{28} \mathrm{O}_{108}\right]^{14-}\left(3^{\prime}\right)$, but most commonly the previously reported and thermodynamically favourable $\left[\mathrm{Pd}_{3}\left(\mathrm{TeW}_{9} \mathrm{O}_{33}\right)_{2}\right]^{10-}$ species $^{8 b}$ (see ESI, Fig. S5,$\uparrow$ for a more detailed discussion of these experiments). Taken together these observations suggest that $\mathbf{3}$ is likely to be an interesting, metastable product of this reaction system which, once removed from the mother liquor, can readily transform to form more thermodynamically favourable species in solution. Whilst a comprehensive exploration of this reaction system will not be provided here, we hope to report it in detail at a later date.

\section{Electrochemistry}

Cyclic voltammetry (CV) was also employed as a means to explore the electrochemical behaviour of these clusters. Due to the instability of $\mathbf{3}$ and the difficulty in ensuring that a single species is being measured in solution, we cannot accurately report the electrochemical behaviour of this compound here. $\mathrm{CV}$ of compounds 1 and 2 was performed in $0.2 \mathrm{M} \mathrm{NaSO}_{4}$ solution and, as expected, no significant difference was found between the two species in which the electrochemical behaviour was dominated by irreversible Pd-centred redox processes (Fig. S6 $\dagger$ ). Scanning of the potential in the negative direction leads to a single broad irreversible cathodic peak centred at $-0.45 \mathrm{~V}$ corresponding to the reduction of the $\mathrm{Pd}^{\mathrm{II}}$ centres in 1 to $\mathrm{Pd}^{0}$ and an electrodeposition process on the working electrode. Notably, this occurs at a slightly lower potential than is normally reported in the literature ${ }^{11 g, 13 c, d}$ and whilst it is possible that trapping the $\left\{\mathrm{Pd}_{5} \mathrm{Se}_{2}\right\}$ species within the tungstate framework does have an overall effect on its electrochemical behaviour, it has been noted in multiple previous studies that electrochemical reduction and oxidation of Pd-species is a particularly complex process and it is therefore difficult to draw conclusions from this study alone. ${ }^{19}$ As the scan proceeds in the positive direction, two oxidation waves can be observed at $+0.60 \mathrm{~V}$ and $+0.88 \mathrm{~V}$ respectively. These correspond to the reoxidation of $\mathrm{Pd}^{0}$ and the formation of resulting oxides, which tallies well with that which has previously been reported in related systems. This is further confirmed by the appearance of a second cathodic wave at $+0.21 \mathrm{~V}$ which is characteristic of the reduction of PdO.

\section{Conclusions}

In conclusion, we have presented three new Pd-containing polyoxotungstate species which are the highest nuclearity noble-metal containing polyanions to have been isolated thus far. A one-pot reaction strategy exploiting the structure directing effects of $\mathrm{Se}^{\mathrm{IV}}$ template heteroatoms has allowed us to trap a $\left\{\mathrm{Pd}_{5} \mathrm{Se}_{2}\right\}$ unit within a robust selenotungstate species, providing an interesting mechanistic insight into the formation of the related class of polyoxopalladate materials and combining, for the first time in a single POM architecture, two distinct lacunary 'building blocks' from different parent anions. Further experiments using the coordinatively flexible $\mathrm{Te}^{\mathrm{IV}}$ heteroatom template and linker have allowed us to isolate a metastable tellurotungstate hexamer containing two unique $\left\{\mathrm{Pd}_{3} \mathrm{Te}_{3} \mathrm{O}_{3}\right\}$ moieties and allowing us to draw insights into the assembly of both this species and a previously reported, related class of tellurotungstate macrocycles assembled from the same unusual $\left\{\mathrm{TeW}_{7}\right\}$ units. We believe that this approach could be an important new means to isolate a new series of complex transition metal substituted polyoxometalate species, in which the assembly processes are not governed by stable, well-defined, pre-synthesised lacunary building blocks but by the dynamic, combinatorial solution chemistry of lone-pair containing heteropolyoxometalates synthesised via a bottomup approach under one-pot conditions.

\section{Experimental section}

\section{Materials and physical measurements}

All reagents were purchased commercially and used without further purification. Elemental analyses for Pd and $\mathrm{W}$ were conducted on an Agilent 7700x ICP-MS and alkali metal content was determined on a Sherwood Scientific M410 INDUSTRIAL flame photometer. Thermogravimetric analysis was conducted using a TA Instruments Q500 Thermogravimetric Analyser at a heating rate of $10{ }^{\circ} \mathrm{C} \mathrm{min}^{-1}$ under air. FT-IR spectra were collected on a Shimadzu FTIR $8400 \mathrm{~s}$ spectrometer fitted with a golden gate ATR attachment. Electrospray ionisation mass spectrometry (ESI-MS) was performed on a Bruker micrOTOF-Q spectrometer (full details of MS measurements available in ESI $\dagger$ ). Cyclic voltammetry was performed on a $\mathrm{CH}$ Instruments $600 D$ potentiostat using a standard three electrode set-up, with a $3 \mathrm{~mm}$ diameter glassy carbon working electrode and Pt wire counter electrode, with all potentials quoted against an Ag/ $\mathrm{AgCl}$ reference electrode. All measurements were performed at room temperature in thoroughly de-aerated solutions under a positive pressure of dry $\mathrm{Ar} / \mathrm{N}_{2}$.

Synthesis of $\mathrm{K}_{28}\left[\mathrm{H}_{12} \mathrm{Pd}_{10} \mathrm{Se}_{10} \mathrm{~W}_{52} \mathrm{O}_{206}\right] \cdot 65 \mathrm{H}_{2} \mathrm{O}$ (1). $\mathrm{K}_{2} \mathrm{WO}_{4}$ $(1.00 \mathrm{~g}, 3.07 \mathrm{mmol})$ and $\mathrm{K}_{2} \mathrm{SeO}_{3}(0.16 \mathrm{~g}, 0.79 \mathrm{mmol})$ were dissolved in $30 \mathrm{ml} \mathrm{H}_{2} \mathrm{O}$. The $\mathrm{pH}$ of the resulting solution was adjusted to 5.8 by $70 \% \mathrm{HNO}_{3} \cdot \quad \mathrm{Pd}\left(\mathrm{NO}_{3}\right)_{2} \cdot \mathrm{H}_{2} \mathrm{O} \quad(0.11 \mathrm{~g}$, $0.44 \mathrm{mmol}$ ) was added into the solution, whose $\mathrm{pH}$ value was then adjusted to 4.0 by $70 \% \mathrm{HNO}_{3}$. The solution was then heated and stirred at $95{ }^{\circ} \mathrm{C}$ for 50 minutes, cooled down to 
room temperature, filtered and left for evaporation. Red rectangular-shaped crystals of $\mathbf{1}$ were obtained within one week. Yield: $0.18 \mathrm{~g}$ (18\% based on W). I.R. (in $\left.\mathrm{cm}^{-1}\right)$ : 3438 (b), 1623 (m), 1381 (m), 962 (m), 891 (s), 830 (s), 781 (s), 706 (s). Elemental analysis, calc. for $\mathrm{H}_{142} \mathrm{~K}_{28} \mathrm{O}_{271} \mathrm{Pd}_{10} \mathrm{Se}_{10} \mathrm{~W}_{52}$ : K 6.44, Pd 6.26, W 56.28\%. Found K 6.51, Pd 6.24, W 56.30\%. TGA water loss from 20 to $200{ }^{\circ} \mathrm{C}$, calculated (found) \%: 6.9 (6.7).

Isolation of $\mathrm{K}_{26}\left[\mathrm{H}_{14} \mathrm{Pd}_{10} \mathrm{Se}_{10} \mathrm{~W}_{52} \mathrm{O}_{206}\right] \cdot 68 \mathrm{H}_{2} \mathrm{O}$ (2). Compound 2 may be isolated from the same mother liquor as $\mathbf{1}$. Once crystals of 1 had been isolated, the remaining solution was allowed to continue to slowly evaporate at room temperature. Red block crystals of 2 were obtained within two weeks. Yield: $0.11 \mathrm{~g}$ (11\% based on W). I.R. (in $\left.\mathrm{cm}^{-1}\right)$ : 3483 (b), 1619 (m), 1387 (m), 970 (s), 891 (s), 827 (s), 764 (s), 712 (s). Elemental analysis, calc. for $\mathrm{H}_{150} \mathrm{~K}_{26} \mathrm{O}_{274} \mathrm{Pd}_{10} \mathrm{Se}_{10} \mathrm{~W}_{52}$ : $\mathrm{K}$ 5.99, $\mathrm{Pd} 6.27, \mathrm{~W}$ $56.35 \%$. Found $\mathrm{K} 5.91$, Pd 6.23, W 56.11\%. TGA water loss from 20 to $200{ }^{\circ} \mathrm{C}$, calculated (found) \%: 7.2 (7.2).

Synthesis of $\mathbf{N a}_{40}\left[\mathrm{Pd}_{6} \mathrm{Te}_{19} \mathrm{~W}_{42} \mathrm{O}_{190}\right] \cdot 76 \mathrm{H}_{2} \mathrm{O}$ (3). $\mathrm{Na}_{2} \mathrm{WO}_{4}$. $2 \mathrm{H}_{2} \mathrm{O}(2.0 \mathrm{~g}, 6.06 \mathrm{mmol})$ and $\mathrm{Na}_{2} \mathrm{TeO}_{3}(0.2 \mathrm{~g}, 0.90 \mathrm{mmol})$ were dissolved in $30 \mathrm{ml} \mathrm{H}_{2} \mathrm{O}$. The $\mathrm{pH}$ of the resulting solution was adjusted to 4.4 by $70 \% \quad \mathrm{HNO}_{3} \cdot \quad \mathrm{Pd}\left(\mathrm{NO}_{3}\right)_{2} \cdot \mathrm{H}_{2} \mathrm{O} \quad(0.1 \mathrm{~g}$, $0.38 \mathrm{mmol}$ ) was added to the solution, whose $\mathrm{pH}$ value was then readjusted to 5.6 by $4 \mathrm{M} \mathrm{NaOH}$ and maintained at this value for $10 \mathrm{~min}$. The resulting deep red/brown solution was then filtered and allowed to stand for evaporation. Thin, very fragile, golden coloured crystals were obtained within 2-4 weeks. Yield: $0.06 \mathrm{~g}$ ( $3 \%$ based on $\mathrm{W})$. Note that this yield refers to the first crop of crystals only, continued evaporation will continue to yield product which can be subsequently isolated though the total yield of pure, crystalline product in this reaction rarely exceeds significantly more than 5-6\%. I.R. (in $\mathrm{cm}^{-1}$ ): 3395 (b), 1628 (m), 1400 (m), 1367 (m), 937 (m), 820 (s), 743 (s), 668 (s), 639 (s). Elemental analysis, calc. for $\mathrm{H}_{152} \mathrm{Na}_{40} \mathrm{O}_{266} \mathrm{Pd}_{6} \mathrm{Te}_{19} \mathrm{~W}_{42}$ : Na 5.71, Pd 3.96, W 47.92\%. Found $\mathrm{Na} 5.66, \mathrm{Pd} 3.81, \mathrm{~W} 48.45 \%$. TGA water loss from 20 to $200{ }^{\circ} \mathrm{C}$, calculated (found) \%: 8.5 (8.5).

\section{X-ray crystallography}

Single crystals of compounds $\mathbf{1}$ and $\mathbf{2}$ were mounted in oil on a glass capillary and datasets were collected on an Oxford Diffraction Gemini A Ultra diffractometer (with ATLAS CCD detector), whilst 3 was mounted in oil on a flexible mount loop and data was collected on a Bruker Apex II diffractometer (with Quazar CCD detector), equipped with a graphite monochromator $\left(\lambda\left(\mathrm{Mo}_{\mathrm{K} \alpha}\right)=0.71073 \AA\right)$. All measurements were conducted at 150(2) K. Absorption effects for datasets 1 and 2 were corrected via an analytical method using a multifaceted crystal model, ${ }^{20}$ whilst corrections were applied to compound 3 via an empirical method $^{21}$ and data reductions performed using the CrysAlisPro or Apex2 software respectively. All structures were solved by direct methods and structural refinement was carried out using SHELX-97 by means of a full matrix least squares on $F^{2}$ method, ${ }^{22}$ performed within the WinGX software suite. ${ }^{23}$ Selected details of the data collection and structural refinement of compounds 1-3 can be found within the ESI (Table S1†) and full details are available in the corresponding
CIF files. Crystallographic data (excluding structure factors) have been deposited (ICSD 426772-426774).

\section{Acknowledgements}

We thank the EPSRC funding (grants EP/H024107/1; EP/ I033459/1; EP/J015156/1), EU FP7 Micreagents (318671), the Chinese Scholarship Council, WestCHEM and the University of Glasgow for supporting this work. LC also thanks the RoyalSociety Wolfson Foundation for a Merit Award. The authors would also like to thank Dr Jun Yan (Zhongnan University) for useful discussions and preliminary help.

\section{Notes and references}

1 (a) M. T. Pope and A. Müller, Angew. Chem., Int. Ed., 1991, 30, 34-48; (b) J. Livage, Coord. Chem. Rev., 1998, 178-180 (Part 2), 999-1018; (c) C. P. Pradeep, D.-L. Long and L. Cronin, Dalton Trans., 2010, 39, 9443-9457; (d) A. Müller and P. Gouzerh, Chem. Soc. Rev., 2012, 41, 7431-7463.

2 (a) D.-L. Long, E. Burkholder and L. Cronin, Chem. Soc. Rev., 2007, 36, 105-121; (b) U. Kortz, A. Müller, J. van Slageren, J. Schnack, N. S. Dalal and M. Dressel, Coord. Chem. Rev., 2009, 253, 2315-2327; (c) D.-L. Long, R. Tsunashima and L. Cronin, Angew. Chem., Int. Ed., 2010, 49, 1736-1758.

3 (a) Special edition: C. L. Hill (guest ed.), Chem. Rev., 1998, 98, 1-390; (b) J. T. Rhule, C. L. Hill, D. A. Judd and R. F. Schinazi, Chem. Rev., 1998, 98, 327-358; (c) Special edition: U. Kortz (guest ed.), Eur. J. Inorg. Chem., 2009, 2009, 5055-5276; (d) Special edition: L. Cronin and A. Müller (guest ed.), Chem. Soc. Rev., 2012, 41, 7325-7648; (e) Special edition: D.-L. Long and L. Cronin (guest ed.), Dalton Trans., 2012, 41, 9799-10106; (f) C. Streb, Dalton Trans., 2012, 41, 1651-1659.

4 (a) S. G. Mitchell, P. I. Molina, S. Khanra, H. N. Miras, A. Prescimone, G. J. T. Cooper, R. S. Winter, E. K. Brechin, D.-L. Long, R. J. Cogdell and L. Cronin, Angew. Chem., Int. Ed., 2011, 50, 9154-9157; (b) L. Vilà-Nadal, S. G. Mitchell, A. Rodriguez-Fortea, H. N. Miras, L. Cronin and J. M. Poblet, Phys. Chem. Chem. Phys., 2011, 13, 2013620145; (c) H. N. Miras, M. Sorus, J. Hawkett, D. O. Sells, E. J. L. McInnes and L. Cronin, J. Am. Chem. Soc., 2012, 134, 6980-6983; (d) J. M. Cameron, G. N. Newton, C. Busche, D.-L. Long, H. Oshio and L. Cronin, Chem. Commun., 2013, 49, 3395-3397.

5 (a) M. Ishaque Khan, S. Cevik and R. Hayashi, Dalton Trans., 1999, 1651-1654; (b) I. A. Weinstock, J. J. Cowan, E. M. G. Barbuzzi, H. Zeng and C. L. Hill, J. Am. Chem. Soc., 1999, 121, 4608-4617; (c) S. Uchida, M. Hashimoto and N. Mizuno, Angew. Chem., Int. Ed., 2002, 41, 2814-2817; (d) D.-L. Long, P. Kögerler, A. D. C. Parenty, J. Fielden and L. Cronin, Angew. Chem., Int. Ed., 2006, 45, 4798-4803; (e) N. Leclerc-Laronze, J. Marrot, G. Hervé, R. Thouvenot and E. Cadot, Chem.-Eur. J., 2007, 13, 7234-7245; 
(f) D.-L. Long, Y.-F. Song, E. F. Wilson, P. Kögerler, S.-X. Guo, A. M. Bond, J. S. J. Hargreaves and L. Cronin, Angew. Chem., Int. Ed., 2008, 47, 4384-4387; (g) B. S. Bassil and U. Kortz, Dalton Trans., 2011, 40, 9649-9661.

6 (a) D.-L. Long, P. Kögerler and L. Cronin, Angew. Chem., Int. Ed., 2004, 43, 1817-1820; (b) D.-L. Long, H. Abbas, P. Kögerler and L. Cronin, Angew. Chem., Int. Ed., 2005, 44, 3415-3419; (c) C. Baffert, J. F. Boas, A. M. Bond, P. Kögerler, D.-L. Long, J. R. Pilbrow and L. Cronin, Chem.Eur. J., 2006, 12, 8472-8483; (d) C. Fleming, D.-L. Long, N. McMillan, J. Johnston, N. Bovet, V. Dhanak, N. Gadegaard, P. Kögerler, L. Cronin and M. Kadodwala, Nat. Nanotechnol., 2008, 3, 289-233; (e) J. Thiel, C. Ritchie, C. Streb, D.-L. Long and L. Cronin, J. Am. Chem. Soc., 2009, 131, 4180-4181; $(f)$ L. Vilà-Nadal, K. Peuntinger, C. Busche, J. Yan, D. Lüders, D.-L. Long, J. M. Poblet, D. M. Guldi and L. Cronin, Angew. Chem., Int. Ed., 2013, 52, 9695-9699.

7 (a) K. Wassermann, M. H. Dickman and M. T. Pope, Angew. Chem., Int. Ed., 1997, 36, 1445-1448; (b) J. Yan, J. Gao, D.-L. Long, H. N. Miras and L. Cronin, J. Am. Chem. Soc., 2010, 132, 11410-11411; (c) J. Yan, D.-L. Long and L. Cronin, Angew. Chem., Int. Ed., 2010, 49, 4117-4120; (d) J. Gao, J. Yan, S. G. Mitchell, H. N. Miras, A. G. Boulay, D.-L. Long and L. Cronin, Chem. Sci., 2011, 2, 1502-1508; (e) M. N. Corella-Ochoa, H. N. Miras, A. Kidd, D.-L. Long and L. Cronin, Chem. Commun., 2011, 47, 8799-8801.

8 (a) A. C. Stowe, S. Nellutla, N. S. Dalal and U. Kortz, Eur. J. Inorg. Chem., 2004, 2004, 3792-3797; (b) J. Gao, J. Yan, S. Beeg, D.-L. Long and L. Cronin, Angew. Chem., Int. Ed., 2012, 51, 3373-3376; (c) J. Gao, J. Yan, S. Beeg, D.-L. Long and L. Cronin, J. Am. Chem. Soc., 2012, 135, 1796-1805; (d) W.-C. Chen, H.-L. Li, X.-L. Wang, K.-Z. Shao, Z.-M. Su and E.-B. Wang, Chem.-Eur. J., 2013, 19, 1100711015.

9 H. Lv, Y. V. Geletii, C. Zhao, J. W. Vickers, G. Zhu, Z. Luo, J. Song, T. Lian, D. G. Musaev and C. L. Hill, Chem. Soc. Rev., 2012, 41, 7572-7589.

10 (a) T. M. Anderson, W. A. Neiwert, M. L. Kirk, P. M. B. Piccoli, A. J. Schultz, T. F. Koetzle, D. G. Musaev, K. Morokuma, R. Cao and C. L. Hill, Science, 2004, 306, 2074-2077; (b) R. Neumann and A. M. Khenkin, Inorg. Chem., 1995, 34, 5753-5760; (c) R. Neumann and M. Dahan, Nature, 1997, 388, 353-355; (d) C. Dablemont, A. Proust, R. Thouvenot, C. Afonso, F. Fournier and J.-C. Tabet, Inorg. Chem., 2004, 43, 3514-3520; (e) T. Kurata, A. Uehara, Y. Hayashi and K. Isobe, Inorg. Chem., 2005, 44, 2524-2530; $(f)$ Y. V. Geletii, B. Botar, P. Kögerler, D. A. Hillesheim, D. G. Musaev and C. L. Hill, Angew. Chem., Int. Ed., 2008, 47, 3896-3899; (g) A. Sartorel, M. Carraro, G. Scorrano, R. D. Zorzi, S. Geremia, N. D. McDaniel, S. Bernhard and M. Bonchio, J. Am. Chem. Soc., 2008, 130, 5006-5007; (h) A. E. Kuznetsov, Y. V. Geletii, C. L. Hill, K. Morokuma and D. G. Musaev, J. Am. Chem. Soc., 2009, 131, 6844-6854; (i) S. Angus-Dunne, R. C. Burns, D. C. Craig and G. A. Lawrance, Z. Anorg. Allg. Chem., 2010, 636, 727-734; $(j)$ T. Hirano, K. Uehara,
K. Kamata and N. Mizuno, J. Am. Chem. Soc., 2012, 134, 6425.

11 (a) L.-H. Bi, U. Kortz, B. Keita, L. Nadjo and H. Borrmann, Inorg. Chem., 2004, 43, 8367-8372; (b) L.-H. Bi, M. Reicke, U. Kortz, B. Keita, L. Nadjo and R. J. Clark, Inorg. Chem., 2004, 43, 3915-3920; (c) L.-H. Bi, U. Kortz, B. Keita, L. Nadjo and L. Daniels, Eur. J. Inorg. Chem., 2005, 2005, 3034-3041; (d) L.-H. Bi, M. H. Dickman and U. Kortz, CrystEngComm, 2009, 11, 965-966; (e) R. Villanneau, S. Renaudineau, P. Herson, K. Boubekeur, R. Thouvenot and A. Proust, Eur. J. Inorg. Chem., 2009, 2009, 479-488; (f) N. V. Izarova, A. Banerjee and U. Kortz, Inorg. Chem., 2011, 50, 10379-10386; (g) S. Duval, J. Marrot, C. SimonnetJegat, I. M. Mbomekalle, M. Sokolov and E. Cadot, Dalton Trans., 2012, 41, 3174-3184.

12 (a) P. Putaj and F. Lefebvre, Coord. Chem. Rev., 2011, 255, 1642-1685; (b) N. V. Izarova, M. T. Pope and U. Kortz, Angew. Chem., Int. Ed., 2012, 51, 9492-9510.

13 (a) E. V. Chubarova, M. H. Dickman, B. Keita, L. Nadjo, F. Miserque, M. Mifsud, I. W. C. E. Arends and U. Kortz, Angew. Chem., Int. Ed., 2008, 47, 9542-9546; (b) N. V. Izarova, R. N. Biboum, B. Keita, M. Mifsud, I. W. C. E. Arends, G. B. Jameson and U. Kortz, Dalton Trans., 2009, 9385-9387; (c) N. V. Izarova, M. H. Dickman, R. N. Biboum, B. Keita, L. Nadjo, V. Ramachandran, N. S. Dalal and U. Kortz, Inorg. Chem., 2009, 48, 7504-7506; (d) M. Barsukova, N. V. Izarova, R. N. Biboum, B. Keita, L. Nadjo, V. Ramachandran, N. S. Dalal, N. S. Antonova, J. J. Carbó, J. M. Poblet and U. Kortz, Chem.-Eur. J., 2010, 16, 9076-9085; (e) M. Barsukova-Stuckart, N. V. Izarova, R. Barrett, Z. Wang, J. van Tol, H. W. Kroto, N. S. Dalal, B. Keita, D. Heller and U. Kortz, Chem.-Eur. J., 2012, 18, 6167-6171; $(f)$ M. Barsukova-Stuckart, N. V. Izarova, R. A. Barrett, Z. Wang, J. van Tol, H. W. Kroto, N. S. Dalal, P. Jiménez-Lozano, J. J. Carbó, J. M. Poblet, M. S. von Gernler, T. Drewello, P. de Oliveira, B. Keita and U. Kortz, Inorg. Chem., 2012, 51, 13214-13228; (g) Z.-G. Lin, B. Wang, J. Cao, B.-K. Chen, Y.-Z. Gao, Y.-N. Chi, C. Xu, X.-Q. Huang, R.-D. Han, S.-Y. Su and C.-W. Hu, Inorg. Chem., 2012, 51, 4435-4437.

14 (a) F. Xu, R. A. Scullion, J. Yan, H. N. Miras, C. Busche, A. Scandurra, B. Pignataro, D.-L. Long and L. Cronin, J. Am. Chem. Soc., 2011, 133, 4684-4686; (b) F. Xu, H. N. Miras, R. A. Scullion, D.-L. Long, J. Thiel and L. Cronin, Proc. Natl. Acad. Sci. U. S. A., 2012, 109, 11609-11612.

15 R. Q. Cabrera, D.-L. Long, L. Cronin and P. F. McMillan, CrystEngComm, 2010, 12, 2568-2572.

16 M. Delferro, C. Graiff, L. Elviri and G. Predieri, Dalton Trans., 2010, 39, 4479-4481.

17 The combination of multiple inequivalent lacunary fragments within a single POM framework is relatively uncommon but it has been demonstrated in several previous instances, mostly within the structurally labile silicotungstate series of HPOMs (see ref. $4 a, 5 e$ for example). Combining lacunary building blocks from different parent clusters has however proven to be a considerable challenge as a 
result of the differing range of $\mathrm{pH}$ under which Keggin and Wells-Dawson fragments are generally stable.

18 This phenomena is common, particularly in high nuclearity POM clusters, and we have observed it before in related previous work (see ref. $8 b, c$ for example). Whilst this makes accurate absolute peak assignments difficult, the relationship of the major peaks in each spectrum allows us to unambiguously identify them as sequentially charged anions containing the cluster of interest, particularly where the peak envelope is poorly resolved or especially broadened.
19 (a) A. E. Bolzán and A. J. Arvia, J. Electroanal. Chem., 1992, 322, 247-265; (b) C.-C. Hu and T.-C. Wen, Electrochim. Acta, 1996, 41, 1505-1514.

20 R. C. Clark and J. S. Reid, Acta Crystallogr., Sect. A: Found. Crystallogr., 1995, 51, 887-897.

21 R. Blessing, Acta Crystallogr., Sect. A: Found. Crystallogr., 1995, 51, 33-38.

22 G. Sheldrick, Acta Crystallogr., Sect. A: Found. Crystallogr., 2008, 64, 112-122.

23 L. J. Farrugia, J. Appl. Crystallogr., 1999, 32, 837-838. 